Portland State University

PDXScholar

Criminology and Criminal Justice Faculty

Publications and Presentations

Criminology and Criminal Justice

2016

\title{
Can Expert Testimony Sensitize Jurors to Variations in Confession Evidence
}

\author{
Kelsey S. Henderson \\ Portland State University, kelsey.henderson@pdx.edu \\ Lora M. Levett \\ University of Florida
}

Follow this and additional works at: https://pdxscholar.library.pdx.edu/ccj_fac

Part of the Criminology and Criminal Justice Commons

Let us know how access to this document benefits you.

\begin{abstract}
Citation Details
PREPRINT Henderson, K. S., \& Levett, L. M. (2016). Can Expert Testimony Sensitize Jurors to Variations in Confession Evidence? Law and Human Behavior, 40(6), 638-649. http://dx.doi.org/10.1037//hb0000204
\end{abstract}

This Pre-Print is brought to you for free and open access. It has been accepted for inclusion in Criminology and Criminal Justice Faculty Publications and Presentations by an authorized administrator of PDXScholar. Please contact us if we can make this document more accessible: pdxscholar@pdx.edu. 
PREPRINT Henderson, K. S., \& Levett, L. M. (2016). Can Expert Testimony Sensitize Jurors tol Variations in Confession Evidence? Law and Human Behavior, 40(6), 638-649. http://dx.doi.org/10.1037/lhb0000204

\title{
Can Expert Testimony Sensitize Jurors to Variations in Confession Evidence?
}

\begin{abstract}
Confession evidence can be extremely damaging in the courtroom; jurors are more willing to convict based on the presence of a confession than eyewitness evidence and character testimony (Kassin \& Neumann, 1997). To date, no research has examined whether jurors notice variations in the confession evidence based on whether the confession is consistent or inconsistent with the crime evidence (a likely low quality confession). In study one, mock jurors read a trial summary in which a suspect's confession was consistent or inconsistent with other case facts. Jurors were marginally more likely to convict if the confession and case facts were consistent than if they were not, but did not view the confession differently based on the consistency of the confession and case facts. In study two, we varied whether an expert testified about the consistency of the confession and case facts. Jurors who reported for jury duty did not render different trial decisions or view the confession differently based on the consistency of the confession and case facts or the presence of the expert testimony. We expanded the design in study three to vary the content of the confession in addition to the case facts. Jurors used the consistency of the confession and case facts in making decisions, and expert testimony sensitized jurors to variations in the content of confession evidence on the verdict measure. Findings suggest jurors notice variations in confession evidence and expert testimony shows promise for educating jurors about characteristics of confessions.
\end{abstract}

Keywords: jury-decision making, expert testimony, confessions 


\section{Can Expert Testimony Sensitize Jurors to Variations in Confession Evidence?}

Approximately $25 \%$ of the over 300 people exonerated with the help of the Innocence Project falsely confessed (Innocenceproject.org). Jurors carry the responsibility of assigning proper weight to evidence, and theoretically, jurors should weigh confession evidence based on the quality of the confession. Overall, jurors weigh confessions more heavily than other forms of evidence (i.e., character testimony or eyewitness identification). Thus, confession evidence can be one of the most damaging pieces of evidence proffered at trial (Kassin \& Neumann, 1997).

Given the weight jurors assign to confession evidence, we must ask whether jurors can properly consider the quality of a confession. If jurors have trouble weighing confession evidence appropriately, it is possible that defense attorneys or judges could use trial mechanisms like expert testimony to help educate jurors about indicators of the quality of a confession. The purpose of this paper is to evaluate whether jurors properly weigh confession evidence and whether expert testimony can help jurors improve their decisions about confession evidence.

\section{Jurors' Evaluations of Confession Evidence}

Professionals and laypeople have trouble distinguishing between true and false confessions (Kassin, Meissner, \& Norwick, 2005). In addition, in one study, jurors did not render different verdicts based on whether the confession was admissible or obtained under high or low pressure (Kassin \& Sukel, 1997). Similarly, the circumstances under which the confession was obtained did not affect jurors' verdict ratings in another study (Shaked-Schroer, Costanzo, \& Berger, 2013). However, jurors rated a confession as more coercive in high pressure situations only if the confession did not lead to other inculpating evidence (i.e., the discovery of the murder weapon) (Shaked-Schroer et al., 2013). Thus, across at least two studies, the circumstances under which the confession was obtained did not affect jurors' ultimate trial decisions. However, these studies did not vary indicators of the quality of the confession within the confession itself. 
Confessions should be considered more reliable if they contain more information than just an admission of guilt. Jurors seem to consider this information in weighing confessions. In one study, researchers manipulated the presence of a confession and whether the confession included more or less detail in the context of a trial summary (Appleby, Kassin, \& Hasel, 2013). Participants who heard confession evidence were more likely to convict than those who did not, and participants who heard more detail in a confession were more likely to convict than those who heard less detail (Appleby et al., 2013). Thus, the content of a confession appears to affect jurors' decisions.

Another indicator of a quality confession should be the accuracy of the detail provided in the confession; most false confessions include details about the crime (Appleby et al., 2013). One researcher analyzed the content of proven false confessions, focusing on the presence of non-public details and inconsistencies between the suspect's confession and other evidence (Garrett, 2010). Of the 38 false confessions analyzed, 71\% contained non-public details of the crime and victim (likely obtained from the interrogators; Garrett, 2010). In addition, 28 of the 38 false confessions $(74 \%)$ contained obvious inconsistencies between the confession and the true crime facts (Garrett, 2010), suggesting that inconsistency could be an indicator that the confession may be unreliable. For example, in one false confession, the defendant confessed to murdering his wife after a lengthy interrogation; none of the details he provided matched the physical evidence in the case (Smith, 2014). Similarly, in another false confession, the defendant provided details about the crime scene and victim that were inconsistent with the crime (http://www.innocenceproject.org/Content/Earl_Washington.php). Because jurors weigh confession evidence heavily (Leo \& Liu, 2009), they might not distinguish between confessions with consistent or inconsistent details, although the evidence showing that false confessions 
often contain inconsistent details suggests they should (Garrett, 2010). That is, a confession that is inconsistent with the facts of the case should be considered a low quality confession.

However, the reverse is not always true. That is, a confession that is consistent with the facts of the case does not necessarily mean the confession is valid, as interrogators can inflate the consistency of a suspect's account by providing non-public details during the interrogation (Garrett, 2010). Thus, the inconsistency of a confession and the facts of the case can be used as an indicator of the confession's lower quality, but a confession that is consistent with the case facts may be either a true confession or a confession that was tainted by information gained from investigators or other sources. Thus, the consistency of the confession and case facts is one variable of several that decision makers can use to help weigh the evidence. Confessions that are inconsistent with the case facts should be considered more unreliable than confessions that are consistent with the case facts (Lassiter \& Lingberg, 2010). If a suspect's account of a crime does not match other known crime facts, those inconsistencies should raise a red flag to the investigator and any subsequent decision makers, including jurors. We know that jurors do not correctly consider the circumstances under which a confession is obtained in their trial judgments (Kassin \& Sukel, 1997; Shaked-Schroer et al., 2013), but they do consider the amount of detail in their decision making (Appleby et al., 2013).

In these studies, we examined the effect of the consistency between confession evidence and the facts of the case on jurors' trial decisions. In the first study, we explored whether the consistency of a confession and the facts of the case affected jurors' decisions. In the second study, we manipulated whether jurors heard expert testimony to help them better distinguish between confession evidence that was consistent or inconsistent with the facts of the case. In the 
third study, we varied both the content of the confession and facts of the case to explore the effects of expert testimony on jurors' decisions, counterbalancing for evidence severity.

\section{Study One Overview}

In study one, we varied the presence of confession evidence (present versus absent) in a written trial summary. The content of the confession remained constant in all conditions containing a confession; we varied whether the case facts were the same or different from the confession evidence. By varying the details of the crime and holding the confession details constant, we manipulated whether the confession was consistent or inconsistent with the case facts. After reading the stimulus, participants rendered a verdict and rated their perceptions of trial evidence.

We first predicted a main effect of confession presence on trial decisions such that participants who heard the confession would be more likely than those who did not to convict, rate the strength of the evidence and probability of guilt higher, and the defendant more negatively. Second, we predicted that if jurors weighed the confession appropriately, there would be an effect of the interaction between the case facts manipulation and confession presence on jurors' judgments. Specifically, in confession present conditions, we expected that jurors who heard a confession that was consistent with the case facts would be more likely to find the defendant guilty and would rate the probability of guilt, strength of evidence, and reliability of the confession higher and defendant more negatively compared to jurors who heard a confession that was inconsistent with the case facts. In confession absent conditions, we expected no differences in jurors' ratings on the dependent measures. In addition, if jurors weighed the confession appropriately, jurors should rate the reliability of the confession higher in consistent conditions than inconsistent conditions. 
However, given that jurors do not attend to variations in confession evidence in rendering trial judgments (Kassin \& Sukel, 1997; Schaked-Schroer et al., 2013), it is possible that jurors would not attend to the differences between confessions that are consistent (versus inconsistent) with the facts of the case. If jurors did not properly weigh confession evidence, this would be evidenced by no effect of the interaction between the case facts manipulation and confession presence on jurors' judgments and similar ratings of the confession between consistent and inconsistent conditions.

\section{Study One Method}

\section{Design}

We used a 2 (case facts: less vs. more severe) x 2 (confession: absent vs. present and consistent with less severe case facts) between subjects factorial design. In less severe conditions, the victim was stabbed 1-2 times, was very short, and no witnesses were present. In more severe conditions, the victim was stabbed 38 times, was very tall, and witnesses were present. In confession present conditions, the confession contained details consistent with the less severe case facts. Thus, we created one condition in which the confession and case facts were consistent and one condition in which the confession and case facts were inconsistent.

\section{Participants}

Eighty-five undergraduate university students participated in exchange for course credit. The average age of participants was 20.45 years old (range of 18-35 years of age); participants were $54 \%$ female and $45 \%$ male (one participant declined to report gender). $24 \%$ of participants had been called for jury duty, and $6 \%$ served on a jury.

\section{Materials}

The written trial summary was based on the wrongful conviction case of Earl Washington, Jr. (Washington v. Commonwealth, 1984). In this case, the defendant was convicted 
of rape and murder, two of the most common crimes associated with post-conviction exoneration. This case was chosen because the defendant's false confession was inconsistent with the case facts in the actual case.

The trial stimulus began with judicial instructions, followed by opening statements. The prosecution had five witnesses. First, a police officer and the victim's husband testified about the nature of the victim's injuries and that prior to her death the victim identified her attacker as a black male. Then, two local officers described the interrogation. In all conditions, one officer testified that during interrogation the defendant said he left a handkerchief at the scene of the crime. This was an attempt to provide inculpating evidence in a case with weaker evidence. In all conditions, the defendant claimed he did not own the handkerchief and denied that he identified the handkerchief as his own during interrogation. In addition, on cross-examination, the officer stated that hair found on the handkerchief was tested and did not provide conclusive results.

In conditions containing a confession, the two officers testified that the defendant confessed to murdering the victim. The confession evidence was held constant across conditions; the defendant confessed to stabbing the victim 1-2 times, stated the victim was short, and stated there were no witnesses. In conditions without a confession, this information was omitted.

The officers also described the case facts. Depending on the case facts condition, the officers testified that the victim was stabbed one to two times, was shorter than average, and no witnesses were present (consistent with the confession) or that the victim was stabbed exactly 38 times, was taller than average, and there were witnesses (inconsistent with the confession). The last prosecution witness was the victim's neighbor, who testified that on the afternoon of the crime, she witnessed a man fitting the defendant's description fleeing the victim's home. 
The defense called two witnesses to testify on behalf of the defendant. The first was the defendant, who testified that he did not commit the crime and he had been home alone working at the time of the crime. In the confession present conditions, the defendant admitted to signing a written confession after being interrogated, but asserted that its contents were completely false and that he retracted the confession after signing it. Again, he also asserted that he never recognized the handkerchief as his own. Last, the defendant's sister testified that her brother could not have possibly committed a crime of this nature and that the defendant did not own a handkerchief matching the one in the victim's home. After this testimony, the defense rested, the defense and prosecution gave closing statements, and the judge instructed the jury using pattern jury instructions (http://www.ca6.uscourts.gov/internet/crim_jury_insts/pdf/crmpattjur_full.pdf). To pilot test the stimulus, we presented the condition in which the confession and case facts were consistent to 30 undergraduate students; the conviction rate in this pilot study was $30 \%$.

\section{Dependent Measures}

Verdict, probability of guilt ratings. Participants rendered a verdict (guilty or not guilty) and rated the probability the defendant committed the crime from $0-100 \%$.

Ratings of the defendant. Participants rated the defendant on a series of bipolar adjective pairs (Levett \& Kovera, 2008). Items were on a 7-point scale; higher levels indicated a more positive rating. Items followed by an $(\mathrm{R})$ were reverse coded. Responses to these items were averaged to create a trustworthiness scale $(\alpha=.90)$ : trustworthy-untrustworthy $(\mathrm{R})$, goodnot $\operatorname{good}(\mathrm{R})$, honest-dishonest $(\mathrm{R})$, respectable-not respectable $(\mathrm{R})$, and accurate-inaccurate $(\mathrm{R})$. Responses to these items were averaged to create a likability scale $(\alpha=.76)$ : immoral-moral and unlikable-likable. Responses to these items were averaged to create a believability scale ( $\alpha=$ .82): not believable-believable and not credible-credible. Responses to these items were averaged 
to create a convincingness scale $(\alpha=.83)$ : convincing-unconvincing $(\mathrm{R})$ and sincere-insincere (R). Last, responses to these items were averaged to create a competency scale $(\alpha=.64)$ : certainuncertain (R), intelligent-unintelligent (R), and competent-incompetent (R).

Strength of evidence ratings. For all remaining items, participants indicated agreement with a series of statements on 6-point Likert-type scales with 1 indicating strongly disagree and 6 indicating strongly agree; items followed by an (R) are reverse coded. Responses to these items were averaged to create a strength of evidence scale $(\alpha=.84)$ : (a) In my opinion, the evidence presented by the prosecution was convincing; (b) The defense had a very strong case (R); (c) The evidence presented by the prosecution was not very persuasive (R); (d) In my opinion, the evidence presented by the defense was convincing $(\mathrm{R})$; (e) The evidence presented by the defense was not very persuasive; (f) The prosecution had a very strong case.

Reliability of the confession. Participants' responses to these items were averaged to form a reliability of the confession scale $(\alpha=.85)$ : (a) The suspect's confession is the strongest piece of evidence; (b) The confession in this case proved the suspect committed the crime; (c) The confession evidence in this case is very reliable; (d) I would not be able to find the suspect guilty if he did not confess; (e) Because the suspect confessed, I would not be able to find him not guilty; (f) I believe the suspect in this case actually committed the crime because he confessed.

Manipulation checks. Participants successfully noticed the evidence presented in each condition. Participants in confession conditions were more likely than those who were not to say the defendant confessed ( $86 \%$ vs. $2 \%), \chi^{2}(1, N=86)=61.11, p=0.01, \phi=.84$. Participants who heard less severe evidence were more likely than those who heard more severe evidence to 
say the victim was stabbed $1-2$ times (90\% vs. $2 \%)$ and was short $(90 \%$ vs. $27 \%), \chi^{2}(1, N=86)$

$=64.53, p=0.01, \phi=.88$, and $\chi^{2}(1, N=86)=32.03, p=0.01, \phi=.63$, respectively.

\section{Procedure}

After indicating consent, participants were randomly assigned to one of the four conditions. They filled out a voir dire questionnaire assessing demographic information and past experiences on a jury, read the trial stimulus, and completed the questionnaire. Then, participants were fully debriefed, awarded credit, and thanked for their participation.

\section{Study One Results}

We first corrected the data on the verdict measure due to zero count cells; all participants in two cells of the factorial design found the defendant not guilty. This violates the assumptions of logistic regression. Prior to running analyses, we corrected for this by adding 1 case ( 2 half cases; one .5 guilty verdict and one .5 not guilty verdict) to each cell in the factorial design (Goodman, 1970). For ease of interpretation, we report proportions from the untransformed data.

We first regressed verdict on confession presence, case facts, and the interaction between these two variables in a backwards, stepwise logistic regression. The overall model was significant, $\chi^{2}=11.02, p<.01$. There was an effect of the interaction between confession and case facts on verdict, $B=2.26, S E=0.71$, Wald's $\chi^{2}=10.10, p<0.01, \exp (B)=9.53,95 \% C I$ $[2.37,38.30]$. No other effects were included in the final model. To probe the interaction, we used the MODPROBE macro, which estimates regression coefficients using maximum likelihood and iterates to a result with the Newton-Raphson method for logistic regression (Hayes \& Matthes, 2009). In confession present conditions, participants were more likely to find the defendant guilty in consistent evidence conditions (33\%) versus inconsistent evidence conditions (9\%), although this effect was only marginally significant in follow up analyses, $B=$ 
$1.31, S E=.39, z=1.74, p=.08$. In confession absent conditions, no participants found the defendant guilty, $B=.04, S E=1.45, z=.03, p=.98$.

We ran a MANOVA to test the effect of the independent variables and their interaction on participants' probability of guilt rating and the scale measuring participants' perceptions of the strength of evidence. At the multivariate level, we found main effects of confession, $\lambda=.79$, $F(1,81)=11.07, p<.01, \eta^{2}=.22$, and case facts on the DVs, $\lambda=.92, F(1,81)=3.79, p<.05$ $\eta^{2}=.09$, but no effect of the interaction between these two variables on the DVs, $\lambda=.98, F(1$, $81)=1.03, p=.36, \eta^{2}=.09$. At the univariate level, we found a main effect of confession presence and case facts on participants' probability of guilt and strength of evidence ratings. Participants rated the probability of guilt and strength of evidence higher if a confession was present versus absent (see Table 1). Participants rated the probability of guilt and strength of evidence higher in the less severe crime conditions designed to be consistent with the confession versus the more severe crime conditions designed to be inconsistent with the confession, although these effects were regardless of whether the confession was present (see Table 1).

Next, we ran a MANOVA with confession presence, case facts, and their interaction as the IVs and the five scales representing participants' ratings of the defendant (trustworthiness, likability, believability, convincingness, and competency of the defendant) as DVs. There were no significant main effects or interactions (main effect of confession, $\lambda=.89, F(1,74)=1.87, p$ $=.11, \eta^{2}=.11$, main effect of case facts, $\lambda=.98, F(1,74)=0.36, p=.87, \eta^{2}=.02$, and the effect of the interaction between the IVs, $\left.\lambda=.97, F(1,74)=0.45, p=.81, \eta^{2}=.03\right)$.

To test whether participants rated the reliability of the confession differently based on whether the confession was consistent or inconsistent with the case facts, we selected participants who heard confession evidence and ran a t-test with the case facts manipulation as 
the IV and participants' scaled impressions of the confession as the DV. Participants did not rate the confession differently based on consistency $\left(M_{\text {consistent }}=3.19, S D=1.27, S E=0.29\right.$, $\left.M_{\text {inconsistent }}=3.35, S D=0.97, S E=0.24, t(33)=1.03, p=.11, d=0.14,95 \% C I[-0.57,0.85]\right)$.

In another set of analyses, we completed the same analyses excluding those who failed the manipulation checks $(N=12)$. Results were consistent with results presented here. ${ }^{1}$

\section{Study One Discussion}

In this study, jurors who heard a confession that was consistent with the facts of the case were marginally more likely to find the defendant guilty than those who heard a confession that was inconsistent with the facts of the case. Thus, jurors generally distinguished consistent and inconsistent confessions on the most important measure - verdict. However, there was no effect of the interaction between case facts and confession presence on other measures. Participants' strength of evidence and probability of guilt ratings differed based on the presence or absence of a confession, but not whether that confession was consistent with the facts.

Even though the consistency of the confession and case facts marginally affected jurors' verdict judgments, given the other results, it is possible that jurors did not understand that inconsistencies between the confession and the evidence may indicate the confession is unreliable. Expert testimony on confessions may increase jurors' awareness of consistency as an indicator of an inconsistent confession's quality and provide jurors with a more concrete criterion that they can use in evaluating confession evidence. Previous research on expert testimony and juror decision making may help elucidate how expert testimony may assist jurors in making better decisions.

\section{The Effects of Expert Testimony on Juror Decision Making}

\footnotetext{
${ }^{1}$ Tables for all non-significant results available in online supplemental material Tables 1-5.
} 
Expert testimony generally affects jurors' decisions and evaluations of evidence (Greene, Downey, \& Goodman-Delahunty, 1999; Griffith, Libkuman, \& Poole, 1998; Kovera, Levy, Borgida, \& Penrod, 1994). To date, only a few studies have explored the effect of expert testimony on jurors' decisions in cases with confessions (Blandon-Gitlin, Sperry, \& Leo, 2010; Moffa \& Platania, 2007). These studies analyzed jurors' decisions in cases in which an expert testified on the nature of the interrogation tactics.

In one study, expert testimony had no effect on jurors' verdicts or perceptions of the confession (Moffa \& Platania, 2007). However, another study found a modest effect of expert testimony on jurors' judgments (Blandon-Gitlin et al., 2010). After participants heard expert testimony about the coerciveness of the interrogation, there was a decrease in guilty verdicts and an increase in levels of jurors' perceived coerciveness of the interrogation tactics (Blandon-Gitlin et al., 2010). Thus, expert testimony educated jurors about variations in the circumstances under which the confession was obtained. It is possible that expert testimony about the consistency of confessions with other case facts could educate jurors about this indicator of confession quality. However, it is also possible that expert testimony could have no effect, similar to the findings in the first study (Moffa \& Platania, 2007).

Another possible effect of the expert testimony is that it could make jurors skeptical of all the evidence in question (Cutler, Penrod, \& Dexter, 1989; Levett \& Kovera, 2008; 2009). In studies examining the effect of expert testimony on helping jurors notice variations in another expert's testimony, the presence of expert testimony made jurors skeptical of all the original evidence, regardless of variations in quality (Levett \& Kovera, 2008; 2009). The effect of expert testimony on jurors' decisions about confession evidence could be similar.

\section{Study Two Overview}


In this study, we attempted to replicate and extend the findings in study one by assessing whether expert testimony about the quality of confession evidence would help jurors better evaluate that evidence. In addition, we sampled from jurors who reported for jury duty at a courthouse. We presented jurors with the same stimulus used in study one but also manipulated the presence of a defense expert who testified on the research addressing the consistency of the confession with the case facts. Similar to study one, participants rendered a verdict and rated their perceptions of trial participants and evidence on a number of different scales.

We first predicted to replicate results from study one in conditions without expert testimony, such that jurors would be more likely to render a guilty verdict in conditions in which the case facts and confession were consistent versus inconsistent (although recall the effect was only marginally significant in study one). We also expected participants' other ratings would not largely differ as a function of the interaction between confession presence and the variation in case facts.

Second, for those jurors who heard a confession, we predicted that expert testimony would make jurors more sensitive to variations in the confession evidence. This would be evidenced by an effect of the interaction between expert testimony presence and case facts condition on jurors' decisions in that jurors who heard expert testimony and a confession that was consistent with the case facts would be more likely to find the defendant guilty, rate the probability of guilt, the reliability of the confession, and the strength of the evidence higher and defendant more negatively than jurors who heard expert testimony and a confession that was inconsistent with the case facts.

Conversely, we also predicted that expert testimony may make jurors skeptical of confession evidence. This would be evidenced by a main effect of expert testimony on jurors' 
decisions for those jurors who heard confession evidence, such that jurors who heard expert testimony would be more likely than those who did not to acquit and rate the probability of guilt, reliability of the confession, and strength of evidence lower and defendant more positively than those who did not hear expert testimony. A third possibility, jurors may disregard the expert testimony, which would be evidenced by no effect of expert testimony on jurors' decisions.

\section{Study Two Method}

\section{Participants}

150 community members were recruited from a local courthouse as they were dismissed from jury duty, and were compensated with a \$5.00 gift card for a local coffee shop. Participants were 47.89 years old on average (range of $19-86$ years), $62 \%$ female and $38 \%$ male, and $28 \%$ served on a jury previously. $2 \%$ reported less than a high school degree, $15 \%$ earned a high school degree, $32 \%$ attended some college, $20 \%$ earned an associate's or technical college degree, $17 \%$ earned a bachelor's degree, and $11 \%$ earned a graduate degree.

\section{Design}

For cells containing a confession, we used a 2 (expert testimony: present v. absent) x 2 (case facts: less severe v. more severe) between subjects factorial design. The case facts manipulation was the same as study one, and the confession was consistent with the less severe case facts condition and inconsistent with the more severe case facts condition. We also included two additional cells manipulating the case facts, but without a confession or expert testimony.

\section{Materials}

The written trial summary was the same as the stimulus in study one with the addition of expert testimony in pertinent conditions. In conditions containing expert testimony, a defense expert testified about the prevalence and content of false confessions. The expert informed the 
jury that confessions should be more likely to be judged as unreliable if the suspect's confession and the facts of the case do not match or are inconsistent and as more reliable if the suspect's confession and the facts of the case match or are consistent. The expert testified that jurors could use the consistency of the confession and case facts to weigh the confession.

\section{Dependent Measures}

Verdict, probability of guilt, strength of evidence, and defendant ratings. Participants answered the same verdict, probability of guilt, strength of evidence $(\alpha=.84)$, and ratings of the defendant scales (trustworthiness $(\alpha=.85)$, likability $(\alpha=.62)$, believability $(\alpha=.79)$ convincingness $(\alpha=.78)$ and competency $(\alpha=.58))$ measures presented in study one.

Reliability of the confession. In study one, this measure included no reverse coded items. So, we revised the scale to include all the original items plus the following reverse coded items, scored similarly $(\alpha=.93)$ : (a) The suspect's confession was not the strongest piece of evidence (R); (b) The confession in this case did not prove the suspect committed the crime (R); and (c) The confession evidence in this case is not reliable (R). In addition, one item was revised for clarity: Because the suspect confessed, I would not be able to acquit.

Manipulation checks. Participants again successfully noticed the evidence presented in each condition. Participants in confession conditions were more likely than those who were not to say the defendant confessed (80\% vs. $0 \%), \chi^{2}(1, N=146)=82.03, p=0.01, \phi=.75$. Participants in less severe evidence conditions were more likely than those in more severe evidence conditions to say the victim was stabbed $1-2$ times $(91 \% \mathrm{v} .8 \%), \chi^{2}(1, N=146)=$ 99.62, $p=0.0, \phi=.82$, and was short (94\% v. 34\%), $\chi^{2}(1, N=146)=59.26, p=0.0, \phi=.63$.

As a whole, participants noticed the expert testimony manipulation; $88 \%$ of participants who saw an expert reported that an expert testified at trial, 51\% reported the expert stated that 
reliable confessions matched the facts of the case, and $84 \%$ reported the expert stated that false confessions contain inconsistencies. Due to experimenter error, only participants who received the expert manipulation were asked these questions. Because of this, we presented 51 university students with one of two versions of the stimulus (varying the presence of the expert) in an additional study. Participants who heard an expert testify were more likely than those who did not to say an expert testified $(100 \%$ vs. $39 \%), \chi^{2}(1, N=51)=22.42, p<.01, \phi=.66$.

\section{Procedure}

Participants were recruited as they were dismissed from jury service. Participants who chose to participate indicated consent and were randomly assigned to one of the six conditions. They filled out a voir dire questionnaire assessing demographic information, read a trial stimulus, and completed the questionnaire. Then, participants were fully debriefed and thanked.

\section{Study Two Results}

\section{Do jurors distinguish between confessions consistent and inconsistent with trial facts?}

To test whether we replicated the results presented in study one, we excluded participants who heard an expert testify. Thus, the design for this set of analyses was a: 2 (confession: present v. absent) X 2 (case facts: less severe v. more severe) between subjects factorial design.

We first regressed verdict on confession presence, case facts, and the interaction of these two variables in a backwards stepwise logistic regression. The overall model was significant, $\chi^{2}$ $=-.51, p<.01$. There was a significant main effect for confession, $B=1.51, S E=0.56$, Wald's $\chi^{2}=7.33, p<.01, \exp (B)=4.53,95 \% C I[1.52,13.44]$. Participants were more likely to render a guilty verdict if the defendant confessed to the crime (34\%) versus if he did not (10\%). No other effects were included in the final model. 
We then ran a MANOVA to test the effect of confession presence, case facts, and the interaction between these two variables on participants' probability of guilt rating and the scale measuring participants' perceptions of the strength of evidence. At the multivariate level, we found a main effect for confession presence on the DVs, $\lambda=.93, F(1,92)=3.67, p<.03, \eta^{2}=$ .07. At the univariate level, we found a main effect of confession presence on participants' probability of guilt and strength of evidence ratings; participants rated the probability of guilt and strength of evidence higher if a confession was present versus absent (see Table 2). All other effects were not significant (main effect of case facts, $\lambda=1.00, F(1,92)=0.17, p=.85, \eta^{2}<.01$, and effect of the interaction between the IVs, $\left.\lambda=.99, F(1,92)=0.51, p=.60, \eta^{2}=.01\right)$.

To test the effect of confession presence and evidence consistency on jurors' ratings of the defendant, we ran a MANOVA with confession presence, case facts, and the interaction between these two variables as the IVs and five scales representing participants' perceptions of the defendant as DVs. There were no significant main effects or interactions at the multivariate level (main effect of confession, $\lambda=.90, F(1,80)=1.88, p=.11, \eta^{2}=.11$, main effect of case facts, $\lambda=.99, F(1,80)=0.18, p=.97, \eta^{2}=.01$, and the effect of the interaction between the IVs, $\left.\left.\lambda=.99, F(1,80)=0.14, p=.98, \eta^{2}<.01\right)\right)$.

To test the whether the consistency of the confession and case facts affected jurors' confession ratings, we selected participants who heard the confession and ran a t-test testing the effect of the case facts manipulation on participants' scaled ratings of the confession. Participants did not rate the confession differently based on consistency $\left(M_{\text {consistent }}=2.95, S D=1.42, S E=\right.$ $0.28, M_{\text {inconsistent }}=3.29, S D=1.12, S E=0.22, t(48)=-0.93, p=.36, d=0.27,95 \%$ CI $[-0.29$, $0.82])$.

\section{Does expert testimony sensitize jurors to variations in confession evidence?}


To test whether expert testimony sensitized jurors to variations in confession evidence, we selected participants who heard a confession. Thus, the design reflected a 2 (expert testimony: present v. absent) X 2 (case facts/consistency with the confession: less severe/consistent with the confession v. more severe/inconsistent with the confession) between subjects factorial design.

We first regressed verdict on expert testimony presence, case facts, and the interaction between these two variables in a backwards, stepwise logistic regression. The overall model was not significant, $\chi^{2}=-.51, p=.48$. We then ran a MANOVA to test the effect of expert testimony and case facts and their interaction on participants' probability of guilt rating and the scale measuring participants' perceptions of the strength of evidence. Again, we found no significant multivariate effects of expert testimony presence, case facts, or the interaction between these two variables on jurors' probability of guilt and strength of evidence ratings (main effect of expert testimony, $\lambda=.98, F(1,95)=0.80, p=.46, \eta^{2}=.02 ;$ main effect of case facts, $\lambda=.99, F(1,95)$ $=0.34, p=.71, \eta^{2}<.01 ;$ and the effect of the interaction between the two IVs, $\lambda>.99, F(1,95)$ $\left.=0.22, p=.80, \eta^{2}=.01\right)$. We also tested whether jurors' ratings of the reliability of the confession differed as a function of expert testimony presence, case facts, and the interaction between these two variables in an ANOVA. We found no significant effects of the IVs or their interaction on jurors' ratings (main effect of expert testimony, $F(1,96)=1.56, p=.22, \eta^{2}=.02$, main effect of case facts, $F(1,96)=0.27, p=.61, \eta^{2}<.01$, and the effect of the interaction between the IVs, $\left.F(1,96)=0.84, p=.36, \eta^{2}=.01\right)$.

We then ran a MANOVA with expert testimony presence, case facts, and the interaction as IVs and participants' scaled ratings of the defendant as DVs. We found a significant effect of expert presence on the DVs, $\lambda=.87, F(1,81)=2.41, p<.05, \eta^{2}=.13$. At the univariate level, 
participants in expert present conditions (versus expert absent conditions) rated the defendant as more likeable, $M_{\text {present }}=4.06, S D=1.05, S E=0.17,95 \% C I[3.73,4.39] \mathrm{v} . M_{\text {absent }}=3.53, S D=$ $1.15, S E=0.17,95 \% C I[3.20,3.86], F(1,81)=4.95, p<.03, d=0.48,95 \% C I[0.06,0.90]$ and believable, $M_{\text {present }}=4.12, S D=1.32, S E=0.22,95 \% C I[3.69,4.56]$ v. $M_{\text {absent }}=3.49, S D=$ $1.57, S E=0.22,95 \% C I[3.05,3.92], F(1,81)=4.23, p<.04, d=0.44,95 \% C I[0.01,0.82]$, respectively. All other effects were not significant, main effect of case facts, $\lambda=.98, F(1,81)=$ $0.40, p=.85, \eta^{2}=.02$, and the effect of the interaction between the IVs, $\lambda>.99, F(1,81)=0.24$, $p=.94, \eta^{2}=.02$.

We conducted the analyses for this study a second time excluding those who had failed the confession manipulation check and both of the evidence manipulation checks $(N=26)$. The results from this data set were consistent with the results presented here with two exceptions. In examining the effects of confession presence, case facts, and the interaction between those two variables on jurors' ratings of probability of guilt, strength of the evidence and jurors' ratings of the defendant, excluding those who failed manipulation checks changed the results from significant (reported in the text) to not significant. ${ }^{2}$

\section{Study Two Discussion}

In this study, we partially replicated results from study one. Jurors only rendered different verdicts and trial judgments on the basis of the presence of a confession, and not whether that confession was consistent with the case facts. Thus, these results indicate this sample was more cognizant of the presence of a confession and less attentive to the content of the confession than the sample in study one on the verdict measure. Further, expert testimony did not sensitize jurors to variations in confession evidence. Instead, expert testimony had little effect on any of the

\footnotetext{
${ }^{2}$ Tables for all non-significant results available in online supplemental material Tables 6-19.
} 
dependent measures aside from a few ratings of the defendant; jurors seem to have disregarded the expert testimony on the most important trial measures.

However, this study is not without limitations. One limitation of both study one and study two is that the design intentionally confounded confession-evidence consistency and the severity of the crime. That is, in both studies one and two, the details of the confession were constant and the facts of the case varied to be less severe or more severe; the less severe conditions matched the confession and the more severe conditions did not match the confession. Thus, the severity of the evidence manipulation may actually be suppressing an effect of the consistency of the confession and case facts on the dependent measures. That is, because the consistent condition is also the less severe condition, even if conviction is more likely in conditions in which the case facts and confession are consistent, this may be undetectable because conviction may also be more likely in conditions in which the evidence is more severe (even if the confession is inconsistent with the case facts). Thus, conviction rates could potentially be higher in both conditions, but for different reasons. A second limitation of both studies one and two is a possible lack of power to detect effects. Recent research and recommendations in social psychological literature suggests that most studies using a traditional sample size of 20-25 per cell may be underpowered (and therefore subject to a type II error) (Funder et al., 2014). Thus, the first two studies may not have enough power to detect a significant effect.

Given these limitations and the inconsistencies in results between studies one and two, we conducted a third study. This study was designed to correct for the possible confound in studies one and two by varying the content of the confession and the content of the case facts. In addition, we increased the sample size. Before concluding that experts did not sensitize jurors to variations in confession evidence, we wanted to ensure to maximize power to detect the effect. 


\section{Study Three}

In this study, we presented mock jurors participating online with a trial stimulus in which we varied the presence of expert testimony, content of the defendant's confession, and the case facts. By varying the content of the confession and the content of the case facts, we counterbalanced the severity of the crime with the details provided in the confession. Half of the consistent conditions contained more severe case facts and a confession with more severe details, and the other half of the consistent conditions contained less severe case facts and a confession with less severe details. Further, half of the inconsistent conditions contained less severe case facts and a confession with more severe details, and the other half of the inconsistent conditions contained more severe case facts and a confession with less severe details. Given the presence of a confession had a consistent effect across studies one and two (and has been shown in previous research, see Appleby et al., (2013)), we did not include conditions without a confession.

The hypotheses for this study were identical to the hypotheses for study two in conditions with a confession. If expert testimony helped jurors evaluate confession evidence, we would see an effect of the interaction between expert testimony presence and confession/case facts consistency on jurors' decisions as delineated in the hypotheses for study two. Conversely, if expert testimony did not help jurors evaluate confession evidence, we expected to see either no effect of expert testimony (similar to results from study two) or a skepticism effect, which would be demonstrated by a main effect of expert testimony on jurors' decisions.

\section{Study Three Method}

\section{Participants}

579 jury eligible United States community members completed the survey through Amazon's Mechanical Turk (MTurk) website. MTurk is an online crowdsourcing tool that 
allows individuals to recruit participants to complete a task in exchange for compensation; we paid participants $\$ 0.50$. This source of participants is more demographically diverse compared to traditional college student samples and the data are typically as reliable as data collected via traditional means (Buhrmester, Kwang, \& Gosling, 2011). Because this sample was obtained online, we included three attention questions to ensure participants were attending to the materials. For these questions, participants were instructed to select a particular response option as a way of checking their attention. Participants who answered these questions incorrectly were excluded $(N=80)$. Thus, the final sample included 499 participants.

The average age of the final sample was 38.17 years old (range 18-75 years). The sample was $60 \%$ female and $40 \%$ male. $59 \%$ of participants had been called for jury duty; $19 \%$ had served on a jury. The majority of participants were White (77\%), followed by Black (11\%), Asian (5\%), Hispanic (5\%), and Other (1\%). Highest obtained education level varied; < 1\% reported less than a high school degree, $10 \%$ earned a high school degree, $25 \%$ attended some college, $13 \%$ earned an associate's degree or technical college degree, $31 \%$ earned a bachelor's degree, $3 \%$ attended some graduate school, and $15 \%$ earned a graduate degree.

\section{Design}

We used a 2 (expert testimony: present v. absent) X 2 (confession details: less severe vs. more severe) X 2 (case facts: less severe vs. more severe) between subjects factorial design. In the less severe case facts conditions, the victim was stabbed 1-2 times and was very short; in more severe case facts conditions, the victim was stabbed 38 times and was very tall. The confession details mirrored the case facts manipulation in less severe and more severe conditions. For ease of interpretation, we report results from the simplified design collapsed across consistent and inconsistent conditions: 2 (expert testimony present v. absent) X 2 
(confession-case facts consistency: consistent v. inconsistent). We conducted analyses using the full design and the simplified design, and results were consistent across analyses.

\section{Materials}

We used the same trial stimulus as studies one and two, with a few exceptions. First, we omitted the presence/absence of the witnesses (the victim's children) from the stimulus, because although this occurred in the actual case, it is possible that jurors might question the reliability of children as witnesses or why the witnesses weren't called to testify in the original trial transcript. Second, all participants read a trial transcript containing a confession that varied according to the design described above. Third, even though participants in studies one and two noticed the manipulations as a whole, we had quite a few participants fail manipulation checks. So, we went through the stimulus and strengthened the manipulations by repeating the pertinent information in testimony and opening/closing statements. Fourth, in studies one and two, an officer testified that the defendant admitted to leaving a handkerchief in the victim's home, which the defendant denies (and the handkerchief does not provide any conclusive evidence linking the defendant to the crime). We originally added this in an attempt to increase overall conviction rates. However, given that this could be interpreted as the officer alleging that the defendant admitted to being at the scene of the crime, this evidence could be confusing. So, we omitted it in study three.

\section{Dependent Measures}

Participants rendered the verdict, probability of guilt, strength of evidence $(\alpha=.88)$, and ratings of the defendant (trustworthiness $(\alpha=.84)$, likability $(\alpha=.78)$, believability $(\alpha=.85)$ convincingness $(\alpha=.72)$ competency $(\alpha=.67))$ scales and measures presented in study one. Participants completed the reliability of the confession $(\alpha=.92)$ scale presented in study two. 
Manipulation checks. Participants noticed the manipulations. Participants in less severe evidence conditions were more likely than those in more severe evidence conditions to say the victim was stabbed $1-2$ times $(94 \%$ v. $3 \%), \chi^{2}(1, N=499)=408.03, p=0.01, \phi=-.90$.

Participants who read about a tall victim were more likely to say the victim was tall (93\%) than participants who read about a short victim $(5 \%), \chi^{2}(1, N=497)=384.47, p=0.01, \phi=-.88$.

Participants who read the defendant confessed to stabbing the victim 1-2 times were more likely to report the defendant confessed to stabbing the victim 1-2 times (98\%) than those who read the defendant confessed to stabbing the victim 38 times $(10 \%), \chi^{2}(1, N=498)=384.49, p$ $=0.01, \phi=-.88$. Participants who read the defendant said the victim was tall were more likely report that the defendant said the victim was tall (89\%) than those who read the defendant said the victim was short $(5 \%), \chi^{2}(1, N=498)=352.34, p=0.01, \phi=-.84$.

To further check whether participants noticed if the case facts and confession details were consistent, we coded conditions so we could compare consistent versus inconsistent conditions. Participants in consistent conditions were more likely than those in inconsistent conditions to report that the defendant's confession was consistent with other evidence ( $82 \%$ vs. $12 \%), \chi^{2}(1$, $N=499)=245.76, p=0.01, \phi=-.70$.

Participants who heard an expert testify were more likely than those who did not to say an expert testified $(98 \%$ vs. $33 \%), \chi^{2}(1, \mathrm{~N}=498)=217.17, p=.01, \phi=.66$. Most participants who heard the expert agreed the expert stated that reliable confessions often match the facts of the case (81\%) and that false confessions often contain inconsistencies (91\%).

\section{Procedure}

Participants signed up for the study online and were directed to a qualtrics website to complete the study. After indicating consent, participants were randomly assigned to condition 
and completed a voir dire questionnaire, read the trial stimulus, and answered the trial questionnaire, similar to studies one and two. Then, participants were debriefed and compensated.

\section{Study Three Results}

\section{Does expert testimony sensitize jurors to variations in confession evidence?}

We first ran a backwards, stepwise logistic regression to test the effect of confession-case facts consistency, expert testimony presence, and their interaction on verdict. The overall model was significant, $\chi^{2}=9.58, p<.01$. There was a significant effect of the interaction between confession-case fact consistency and expert testimony on verdict, $B=1.15, S . E=0.40$, Wald's $\chi^{2}=8.56, p<.01, \exp (B)=3.17,95 \% C I[1.46,6.88]$. We probed the interaction using the MODPROBE macro (Hayes \& Matthes, 2009), similar to study one. Participants who heard expert testimony were more likely to convict in conditions in which the confession and case facts were consistent $(M=26 \%)$ versus inconsistent $(M=10 \%), B=1.15, S E=.39, z=2.93, p<.01$. In the expert testimony absent conditions, participants' conviction rates were not significantly different in consistent $(M=21 \%)$ and inconsistent $(M=15 \%)$ conditions, $B=.38, S E=.31, z=$ $1.22, p=.22$. There was also a significant main effect for expert that was not interpretable because it was qualified by the interaction.

We ran a MANOVA to test the effect of expert testimony presence, confession-case facts consistency, and the interaction between these variables on participants' probability of guilt and the scale measuring participants' perceptions of the strength of evidence. There was a significant overall effect of confession-case facts consistency on jurors' ratings, $\lambda=.91, F(1,462)=24.38$, $p<.01, \eta^{2}=.01$. At the scalar level, participants rated the probability of guilt higher and the strength of evidence higher in conditions in which the confession was consistent versus 
inconsistent with the case facts (see Table 3). All other effects were not significant, main effect of expert testimony, $\lambda>.99, F(1,462)=0.23, p=.80, \eta^{2}<.01$, effect of the interaction between the IVs, $\lambda>.99, F(1,462)=0.23, p=.79, \eta^{2}<.01$

Next, we ran an ANOVA with confession-case facts consistency, expert testimony presence, and the interaction between these variables as the IVs and jurors' ratings of the confession as the DV. Participants rated the reliability of the confession higher in conditions in which the confession and case facts were consistent versus inconsistent (see Table 3). All other effects were not significant (main effect of expert testimony, $F(1,455)=0.33, p=.56, \eta^{2}<.01$, effect of the interaction between the IVs, $\left.\left.F(1,455)=0.17, p=.68, \eta^{2}<.01\right)\right)$.

Next, we ran a MANOVA with confession-case facts consistency, expert testimony presence, and the interaction between these two variables as IVs, and jurors' five scaled ratings of the defendant as the DVs. We found significant overall effects of confession-case facts consistency on the DVs, $\lambda=.93, F(5,464)=7.37, p<.01, \eta^{2}=.07$. However, this main effect was qualified by a significant overall effect of the interaction between expert testimony presence and confession-case facts consistency on the DVs, $\lambda=.97, F(5,464)=2.52, p<.03, \eta^{2}=.03$. At the scalar level, the consistency of the confession and case facts significantly affected jurors' ratings of the likability, trustworthiness, believability, convincingness, and competency of the defendant, such that jurors rated the defendant more positively in conditions in which the confession was inconsistent with the case facts compared to conditions in which the confession was consistent with the case facts (see Table 3 for results). The interaction between expert presence and confession case facts consistency significantly affected one measure, the trustworthiness of the defendant, $F(1,468)=9.11, p<.01, \eta^{2}=.02$. Within those conditions containing an expert, jurors rated the defendant more positively if the confession and case facts 
were inconsistent versus consistent, $M_{\text {inconsistent }}=4.28, S D=1.16, S E=0.11,95 \% C I[4.07,4.49]$

v. $M_{\text {consistent }}=3.59, S D=1.03, S E=0.10,95 \% C I[3.40,3.79], d=0.63,95 \% C I[0.35,0.91]$.

The effect of consistency on jurors' ratings of the trustworthiness of the defendant was not significant in conditions without expert testimony, $F(1,468)=0.77, p=.38, \eta^{2}<.01$.

We conducted the analyses a second time excluding those who had failed at least one of the manipulation checks $(N=200)$. Results from this data set were consistent with the results presented here with two exceptions. First, in examining the effects of the IVs and their interaction on jurors' verdict decisions, excluding those who failed manipulation checks changed the results (reported above) to exclude the main effect of expert testimony and include a main effect for consistency; however again, the main effect is not interpretable because of the significant interaction effect. Second, in examining the effects of the IVs and their interaction on jurors' ratings of the reliability of the confession, excluding those who failed manipulation checks changed the results from a significant main effect of consistency to a significant main effect of consistency and a significant main effect of expert testimony presence on ratings of the reliability of the confession (no interaction effect was present). To remain consistent with studies one and two and because the overall meaning of results wasn't changed in the follow up analyses, we chose to include all participants in the final sample. ${ }^{3}$

\section{Study Three Discussion}

In this study, we sought to improve on the design of the first two studies by eliminating the confound between confession-case facts consistency, increasing power to detect significant effects, and strengthening manipulations. Expert testimony sensitized jurors to variations in confession evidence on the verdict measure and in their ratings of the trustworthiness of the defendant. Jurors who heard expert testimony and a confession that was consistent with the case

\footnotetext{
${ }^{3}$ Tables for all non-significant results available in online supplemental material Tables 20-25.
} 
facts were more likely to render guilty verdicts and rate the defendant as less trustworthy compared to jurors who heard expert testimony and a confession that was inconsistent with case facts. Jurors who did not hear expert testimony did not distinguish between confessions that were consistent or inconsistent with the case facts on the verdict measure.

In examining the other dependent measures, jurors distinguished between confessions that were consistent and inconsistent with case facts without the assistance of expert testimony. Specifically, jurors rated the probability of guilt, strength of evidence, and the reliability of the confession higher and characteristics of the defendant more negatively in those conditions containing a confession that was consistent (versus inconsistent) with case facts.

\section{Summary and Concluding Discussion}

Jurors view a confession with details as more reliable than confessions lacking in details, and false confessions often contain detail-laden descriptions (Appleby et al., 2013). In addition, false confessions may contain inconsistencies between the suspect's account and the facts of the case (Garrett, 2010). The studies presented here collectively indicate that jurors are somewhat sensitive to those details, even without the assistance of an expert. In addition, expert testimony may assist jurors in making better decisions about confession evidence.

In study one, we found that jurors were somewhat sensitive to variations in the confession evidence on the verdict measure without the assistance of an expert. Jurors were marginally more likely to render a guilty verdict in conditions in which the confession was consistent with the facts of the crime compared to conditions in which the confession was inconsistent with the facts of the crime. Similarly, in study three, we found that jurors distinguished between a confession that was consistent versus inconsistent with case facts on many measures, rating the probability of guilt, strength of evidence, and reliability of the 
confession higher and some perceptions of the defendant more negatively in conditions with a confession that was consistent with case facts versus conditions with a confession that was inconsistent with the case facts. Further, expert testimony helped to sensitize jurors to the variation in confession evidence on verdict and the perceived trustworthiness of the defendant scale.

Collectively, these studies suggest that jurors are somewhat sensitive to whether the confession is consistent with the case facts in rendering trial decisions. Jurors use the content of the confession in their decision making; jurors were more likely to convict when the defendant's confession contained more versus less detail (Appleby et al., 2013). So, jurors are using the amount of detail and the consistency of that detail with the other facts of the case in at least some decision making at trial.

We also found that expert testimony affected jurors' decisions on some measures. In study two, expert testimony presence affected jurors' ratings of the defendant; jurors believed the defendant was more likeable and believable if an expert testified compared to if there was no expert testimony. However, this did not interact with case facts condition to affect jurors' ratings, suggesting that expert testimony did not sensitize jurors to variations in the content of the confession evidence, but rather made jurors see the defendant more positively overall. Conversely, in study three, we saw that expert testimony sensitized jurors to variations in the content of the confession evidence on the most important measure - verdict. Similarly, expert testimony sensitized jurors to variations in the content of the confession evidence in their ratings of the trustworthiness of the defendant.

In study two, expert testimony did not sensitize jurors to variations in the content of the confession evidence on any of the DVs, and consistency did not affect jurors' trial decisions. 
However expert testimony did help jurors make better decisions in study three. One reason for the inconsistency in results between the studies could be lack of power, the confound, or participants failing to notice the manipulations in study two; all of which we attempted to correct for in study three. If one of the issues was a lack of power in study two, we would not have seen the sensitivity effect of expert testimony due to a type II error. If this was the case, the effect sizes should still be similar between studies two and three. To address this, we tested whether the effect sizes differed between the two studies for the tests of the effect of the interaction between expert testimony presence and the case facts variable (study two) or the case facts/confession consistency variable (study three) on the DVs. We transformed the $\eta^{2}$ values to partial correlations and tested whether the partial correlations were equal (Preacher, 2002, May). We found no significant differences between the effect sizes for the studies across the comparisons: probability of guilt and strength of evidence ratings $z=0.34, p=.76$; reliability of the confession ratings $z=0.56, p=.58$; ratings of the defendant $z=-0.32, p=.75$. Thus, the size of the effect was similar between the two studies, so there likely was not enough power to detect the sensitivity effect in study two.

Thus, is appears that although jurors are somewhat successful in noticing whether a confession is consistent with the other trial evidence on their own, expert testimony further sensitized them to this variation in the content of the confession evidence. To our knowledge, these were the first studies to examine if jurors distinguished between confessions that were consistent or inconsistent with case facts and whether expert testimony would help jurors better evaluate confessions based on this possible indicator of quality. This study is also one of a limited number of studies examining the effect of expert testimony on confession evidence in general; prior studies examined the jurors' perceptions of confession evidence if an expert 
testified about the interrogation tactics used to elicit the confession (Blandon-Gitlin et al., 2010; Moffa, \& Platania, 2007). Taken together, these studies show that even though jurors notice details in the confession evidence on their own, expert testimony can help jurors become more sensitive to variations in the quality of the confession, both in how the confession was obtained (Blandon-Gitlin et al., 2010) and in the consistency of the details provided in the confession with the facts of the case.

\section{Conclusion}

Collectively, these studies show promise for how jurors make decisions about confession evidence. These studies replicated previous results showing that the presence of a confession matters in jurors' decisions (Appleby et al., 2013), and also showed that jurors are somewhat sensitive to variations in the quality of the confession evidence. However, these effects were not entirely consistent across studies and measures, showing that jurors are not always able to distinguish between confessions that are inconsistent or consistent with case facts on their own. Thus, these studies make the need for safeguards within the interrogation room and courtroom salient.

Further, expert testimony shows promise as one of those safeguards in that it sensitized jurors to variations in the consistency of the confession evidence on the verdict measure in study three. However, consistency of the confession and case facts is just one indicator of quality. Even though a confession that is inconsistent with the case facts should be viewed as lower quality, a confession that is consistent with case facts may be tainted by information the suspect gained through other sources, so may not be a high quality confession. Future research could examine how jurors consider and weigh multiple indicators of confession quality, examining how the interactions between these multiple indicators are perceived by jurors and whether expert 
testimony or other safeguards (e.g., jury instructions) sensitizes jurors to those variations in confession evidence.

Future research could also explore why jurors did not consistently use the consistency of the confession and the case facts in their decision making on verdict. That is, if jurors noticed whether a confession was consistent or inconsistent with trial evidence, why did this not reliably affect verdict without the assistance of an expert? Similarly, in previous research, without the aid of expert testimony, jurors did not perceive a confession presented in a trial to be voluntary or fully truthful, but convicted anyway (Blandon-Gitlin et al., 2010). Thus, it appears that even though jurors notice information that should cause them to question the reliability of a confession, they do not necessarily do so without the aid of expert testimony. Theoretically, it is possible that jurors disregard evidence that is inconsistent with the story they developed to account for the evidence. That is, literature on the Story Model for Juror Decision Making shows that jurors arrange evidence into a story-like structure to help them make trial decisions (see Pennington \& Hastie, 1993 for a review). It is possible that the inconsistency of the confession and the case facts or the idea that the confession was not fully voluntary did not fit the story that the defendant confessed because he committed the crime, and so jurors who created this story may have assigned a low weight to this evidence. Future research could address this possibility.

In light of these findings, it remains of the utmost importance to ensure confession evidence is gathered using science based practices and that legal actors understand the indicators of a more or less reliable confession. Science based practices in gathering confession evidence could help reduce the amount of unreliable confession evidence presented to juries. However, collectively, these studies show that jurors have potential for making sound decisions about how to best weigh confession evidence, especially with the assistance of expert testimony. 


\section{Reference List}

Appleby, S., Hasel, L., \& Kassin, S. (2013). Police-induced confessions: An empirical analysis of their content and impact. Psychology, Crime, \& Law, 19(2), 111-128. doi:10.1080/1068316X.2011.613389.

Blandon-Gitlin, I., Sperry, K. \& Leo, R. (2010). Jurors Believe Interrogation Tactics are Not Likely to Elicit False Confessions: Will Expert Witness Testimony Inform Them Otherwise? Psychology, Crime \& Law, 17(3), 239-260. doi: $10.1080 / 10683160903113699$.

Buhrmester, M., Kwang, T., \& Gosling, S.D. (2011). Mechanical turk: A new source of inexpensive, yet high-quality data? Perspectives on Psychological Science, 6(1), 3-5. doi: $10.1177 / 1745691610393980$.

Cutler, B., Penrod, S., \& Dexter, H. (1989). The eyewitness, the expert psychologist, and the jury. Law and Human Behavior, 13(3), 311-332. doi: 10.1007/BF01067032.

Funder, D.C., Levine, J.M., Mackie, D.M., Morf, C.C., Sansone, C., Vazire, S., \& West, S.G. (2013). Improving the dependability of research in personality and social psychology: Recommendations for research and educational practice. Personality and Social Psychology Review, 18(1), 3-12. doi: 10.1177/1088868313507536.

Garrett, B. (2010) The Substance of False Confessions. The Stanford Law Review, 62(4), 10511119. Student Edition. Web. 3 Nov. 2011.

Goodman, L. A. (1970). The multivariate analysis of qualitative data: interactions among multiple classifications. Journal of the American Statistical Association, 65, 226-256. doi: $10.2307 / 2283589$.

Greene, E., Downey, C., \& Goodman-Delahunty, J. (1999). Juror decisions about damages in employment discrimination cases. Behavioral Sciences and the Law, 17(1), 107-121. 
Griffith, J. D., Libkuman, T. M., \& Poole, D. A. (1998). Repressed memories: The effects of expert testimony on mock jurors' decision making. American Journal of Forensic Psychology, 16(1), 5-23.

Hayes, A.F. \& Matthes, J. (2009). Computational procedures for probind interactions in OLS and logistic regression: SPSS and SAS implementations. Behavior Research Methods, 41(3), 924-936. doi: 10.3758/BRM.41.3.924.

http://www.innocenceproject.org

http://www.innocenceproject.org/Content/Earl_Washington.php

Kassin, S. M., Drizin, S. A., Grisso, T., Gudjonsson, G. H., Leo, R. A., \& Redlich, A. D. (2010). Police-induced confessions: Risk factors and recommendations. Law and Human Behavior, 34(1), 3-38. doi:10.1007/s10979-009-9188-6.

Kassin, S.M., Meissner, C., \& Norwick, R. (2005). “I'd Know a False Confession if I Saw One”: A Comparative Study of College Students and Police Investigators. Law and Human Behavior, 29(2), 211-227. doi: 10.1007/s10979-005-2416-9.

Kassin, S. M., \& Neumann, K. (1997). On the power of confession evidence: An experimental test of the fundamental difference hypothesis. Law And Human Behavior, 21(5), 469-484. doi:10.1023/A:1024871622490.

Kassin, S. M., \& Sukel, H. (1997). Coerced confessions and the jury: An experimental test of the 'harmless error' rule. Law and Human Behavior, 21(1), 27-46.

DOI:10.1023/A:1024814009769.

Kovera, M., Levy, R., Borgida, E. \& Penrod, S. (1994). Expert Testimony in Child Sexual Abuse Cases: Effects of expert evidence type and cross-examination. Law and Human Behavior. 18(6), 653-674. doi: 10.1007/BF01499330. 
Lassiter, G., \& Lingberg, M. J. (2010). Video recording custodial interrogations: Implications of psychological science for policy and practice. Journal of Psychiatry \& Law, 38(1/2), 177192. Accessed November 3, 2011.

Leo, R. A., \& Liu, B. (2009). What do potential jurors know about police interrogation techniques and false confessions? Behavioral Sciences \& the Law, 27(3), 381-399. doi: 10.1002/bsl.872

Levett, L., \& Kovera, M. (2008). The effectiveness of opposing expert witnesses for educating jurors about unreliable expert evidence. Law and Human Behavior, 32(4), 363-374. doi: 10.1007/s10979-007-9113-9.

Levett, L. M., \& Kovera, M. (2009). Psychological mediators of the effects of opposing expert testimony on juror decisions. Psychology, Public Policy, And Law, 15(2), 124-148. doi:10.1037/a0016309.

Moffa, M. \& Platania, J. (2007). Effects of Expert Testimony and Interrogation Tactics on Perceptions of Confessions. Psychological Reports, 100(2), 563-570. doi: 10.2466/pr0.100.2.563-570.

Pennington, N., \& Hastie, R. (1993). The story model for juror decision making. In R. Hastie (Ed.), Inside the juror: The psychology of juror decision making (pp. 192-221), New York: Cambridge University Press.

Preacher, K.J. (2002, May). Calculation for the test of the difference between two independent correlation coefficients [Computer software]. Available from http://quantpsy.org.

Shaked-Schroer, N., Costanzo, M., \& Berger, D.E. (2013). Overlooking coerciveness: The impact of interrogation techniques and guilt corroboration on jurors' judgments of coerciveness. Legal and Criminological Psychology. DOI: 10.1111/lcrp.12011. 
Smith, J. (2014, April 25). When Confession Prove False. The Austin Chronicle. Retrieved from http://www.austinchronicle.com/news/2014-04-25/when-confessions-prove-false/

Washington v. Commonwealth, 228 Va. 535, 323 SE2d 577 (1984). 
Table 1

Study One: Means, (Standard Deviations), Standard Errors, and [95\% Confidence Intervals] for Probability of Guilt and Strength of Evidence Ratings as a Function of the Main Effects of Confession and Case Facts

Univariate Effect of Confession

Presence

\begin{tabular}{lcccccc}
\hline Measure & Confession & Confession & $F$ & $d f$ & $p$ & $d$ \\
& Absent & Present & & & & {$[95 \% \mathrm{CI}]$} \\
\hline Probability of & $30.38(17.53)$ & $45.71(25.34)$ & 10.92 & $(1,81)$ & $<.01$ & .70 \\
Guilt & 3.29 & 3.29 & & & {$[0.26,1.14]$} \\
& {$[23.86,36.91]$} & {$[39.18,52.23]$} & & & \\
Strength of & $2.46(0.54)$ & $3.21(0.95)$ & 22.25 & $(1,81)$ & $<.01$ & .97 \\
Evidence & 0.11 & 0.11 & & & {$[0.52,1.42]$} \\
& {$[2.23,2.68]$} & {$[2.99,3.43]$} & & & \\
\end{tabular}

Univariate Effect of Case Facts

\begin{tabular}{lcccccc}
\hline Measure & Less severe & More severe & $F$ & $d f$ & $p$ & $d$ \\
& crime & crime & & & & {$[95 \% \mathrm{CI}]$} \\
\hline Probability of & $42.73(22.42)$ & $33.35(22.82)$ & 4.09 & $(1,81)$ & $<.05$ & -0.41 \\
Guilt & 3.32 & 3.24 & & & & {$[-0.84,0.01]$}
\end{tabular}

$[36.14,49.34] \quad[26.90,39.80]$ 
Strength of

Evidence
$3.05(0.94)$

0.11

$[2.83,3.30]$
$2.61(0.71)$

7.53

$(1,81)$

$<.01$

$-0.53$

0.11

$[-0.96 .-0.10]$ 
Table 2

Study Two: Means, (Standard Deviations), Standard Errors, and [95\% Confidence Intervals], for Probability of Guilt and Strength of Evidence Ratings as a Function of the Main Effect of Confession Presence

Univariate Effect of Confession

Presence

\begin{tabular}{lcccccc}
\hline Measure & Confession & Confession & $F$ & $d f$ & $p$ & $d$ \\
& Absent & Present & & & & {$[95 \%$ CI $]$} \\
\hline Probability of & $32.91(30.12)$ & $47.68(31.74)$ & 5.46 & $(1,92)$ & $<.02$ & .48 \\
Guilt & 4.49 & 4.44 & & & & {$[0.07,0.88]$} \\
& {$[23.99,41.83]$} & {$[38.8,56.50]$} & & & \\
Strength of & $2.70(0.91)$ & $3.23(1.10)$ & 6.50 & $(1,92)$ & $<.01$ & .53 \\
Evidence & 0.15 & 0.15 & & & & {$[0.12,0.93]$} \\
& {$[2.41,3.00]$} & {$[2.94,3.52]$} & & & & \\
\hline
\end{tabular}




\section{Table 3}

Study Three: Means, (Standard Deviations), Standard Errors, and [95\% Confidence Intervals], and Standard Errors for Probability of Guilt, Strength of Evidence, Confession Reliability, and Defendant Ratings as a Function of the Main Effect of Confession-Case Facts Consistency

Univariate Effect of Consistency

\begin{tabular}{|c|c|c|c|c|c|c|}
\hline \multirow[t]{2}{*}{ Measure } & $\begin{array}{l}\text { Confession- } \\
\text { Case Facts }\end{array}$ & $\begin{array}{l}\text { Confession- } \\
\text { Case Facts }\end{array}$ & $F$ & $d f$ & $p$ & \multirow[t]{2}{*}[95\%\mathrm{CI}]{} \\
\hline & Consistent & Inconsistent & & & & \\
\hline Probability of & $41.48(29.18)$ & $24.81(26.43)$ & 40.86 & $(1,462)$ & $<.01$ & -0.60 \\
\hline \multirow[t]{2}{*}{ Guilt } & 1.83 & 1.85 & & & & {$[-0.78,-0.41]$} \\
\hline & {$[37.85,45.05]$} & {$[21.18,28.44]$} & & & & \\
\hline Strength of & $3.12(1.10)$ & $2.49(0.96)$ & 42.74 & $(1,462)$ & $<.01$ & -0.61 \\
\hline \multirow[t]{2}{*}{ Evidence } & 0.68 & 0.68 & & & & {$[-0.80,-0.42]$} \\
\hline & {$[2.98,3.25]$} & {$[2.35,2.62]$} & & & & \\
\hline Reliability of the & 3.02 & 2.44 & 31.58 & $(1,455)$ & $<.01$ & -0.54 \\
\hline \multirow[t]{2}{*}{ Confession } & 0.07 & 0.07 & & & & {$[-0.73,-0.35]$} \\
\hline & {$[2.88,3.15]$} & {$[2.30,2.60]$} & & & & \\
\hline Likability of the & $3.74(1.18)$ & $4.28(1.11)$ & 25.54 & $(1,468)$ & $<.01$ & 0.47 \\
\hline \multirow[t]{2}{*}{ Defendant } & 0.08 & 0.08 & & & & {$[0.29,0.65]$} \\
\hline & {$[3.59,3.89]$} & {$[4.13,4.43]$} & & & & \\
\hline
\end{tabular}




\begin{tabular}{lcccccc} 
Trustworthiness & $3.71(0.97)$ & $4.11(1.10)$ & 17.34 & $(1,468)$ & $<.01$ & 0.39 \\
of the Defendant & 0.07 & 0.07 & & & {$[0.20,0.57]$} \\
& {$[3.58,3.84]$} & {$[3.98,4.25]$} & & & \\
Believability of & $3.92(1.30)$ & $4.61(1.30)$ & 31.84 & $(1,468)$ & $<.01$ & 0.53 \\
the Defendant & 0.09 & 0.09 & & & {$[0.35,0.71]$} \\
& {$[3.76,4.09]$} & {$[4.44,4.78]$} & & & \\
Convincingness & $3.70(1.15)$ & $4.14(1.29)$ & 15.29 & $(1,468)$ & $<.01$ & 0.36 \\
of the Defendant & 0.08 & 0.08 & & & & {$[0.18,0.54]$} \\
& {$[3.55,3.86]$} & {$[3.98,4.30]$} & & & & \\
Competency of & $3.72(1.01)$ & $4.07(1.18)$ & 11.82 & $(1,468)$ & $<.01$ & 0.32 \\
the Defendant & 0.07 & 0.07 & & & & \\
\hline
\end{tabular}

